\title{
CORRIGENDUM
}

\section{Tadalafil is efficacious in Black American and Hispanic men with erectile dysfunction: results from multiple observations in men with erectile dysfunction in National Tadalafil Study in the US (MOMENTUS)}

P Gomery, A Bullock, J McGettigan, R Munarriz, F Natanegara, J Hague, C Kuepfer, S Ahuja and D Wong

International Journal of Impotence Research (2007) 19, 339. doi:10.1038/sj.ijir.3901535

Correction to: International Journal of Impotence Research (2007) 19, 76-83. doi:10.1038/sj.ijir. 3901484
Following the online publication of this article, Dr Ahuja noted that the spelling of his name was incorrect. The complete and correct author names are as above. 